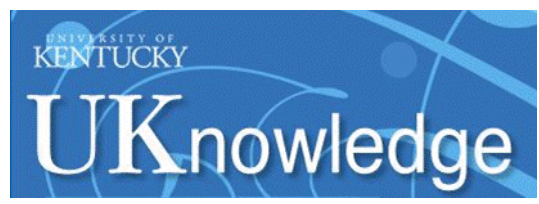

University of Kentucky

UKnowledge

12-15-1985

\title{
Bowen Fluoresence and He II Lines in Active Galaxies and Gaseous Nebulae
}

\author{
Hagai Netzer \\ Royal Greenwich Observatory, United Kingdom \\ Moshe Elitzur \\ University of Kentucky, moshe@pa.uky.edu \\ Gary J. Ferland \\ Ohio State University, gary@uky.edu
}

Follow this and additional works at: https://uknowledge.uky.edu/physastron_facpub

Part of the Astrophysics and Astronomy Commons, and the Physics Commons

Right click to open a feedback form in a new tab to let us know how this document benefits you.

\section{Repository Citation}

Netzer, Hagai; Elitzur, Moshe; and Ferland, Gary J., "Bowen Fluoresence and He II Lines in Active Galaxies and Gaseous Nebulae" (1985). Physics and Astronomy Faculty Publications. 175.

https://uknowledge.uky.edu/physastron_facpub/175

This Article is brought to you for free and open access by the Physics and Astronomy at UKnowledge. It has been accepted for inclusion in Physics and Astronomy Faculty Publications by an authorized administrator of UKnowledge. For more information, please contact UKnowledge@lsv.uky.edu. 
Bowen Fluoresence and He II Lines in Active Galaxies and Gaseous Nebulae

Digital Object Identifier (DOI)

http://dx.doi.org/10.1086/163741

Notes/Citation Information

Published in The Astrophysical Journal, v. 299, no. 2, p. 752-762.

( 1985 . The American Astronomical Society. All rights reserved.

The copyright holder has granted permission for posting the article here.

This article is available at UKnowledge: https://uknowledge.uky.edu/physastron_facpub/175 
The Astrophysical Journal, 299:752-762, 1985 December 15

(C) 1985. The American Astronomical Society. All rights reserved. Printed in U.S.A.

BOWEN FLUORESCENCE AND He II LINES IN ACTIVE GALAXIES AND GASEOUS NEBULAE

\author{
Hagai Netzer ${ }^{1}$ \\ Royal Greenwich Observatory, Herstmonceux Castle, Hailsham, East Sussex \\ Moshe Elitzur \\ Department of Physics and Astronomy, University of Kentucky, Lexington \\ AND \\ GARY J. FERLAND \\ Astronomy Department, Ohio State University \\ Received 1985 March 18; accepted 1985 June 5
}

\begin{abstract}
We have calculated the intensity of $\mathrm{He}$ II and the $\mathrm{O}$ III and $\mathrm{N}$ III Bowen lines under a variety of astrophysical conditions. Our line-transfer method is based on the escape probability formalism and is especially suitable for combining line fluorescence and photoionization calculations in a simple, straightforward way. It reproduces the results of the more sophisticated line-transfer calculations quite accurately and is much better for producing realistic ionization and thermal structures. An extensive grid of models is presented and discussed, with special emphasis on the case of active galactic nuclei (AGNs). Many $\mathrm{O}$ III and $\mathrm{N}$ III Bowen lines are predicted to be strong and detectable in Seyfert galaxies and quasars. In particular, $\mathrm{O}$ III $\lambda 3133$ is calculated to be up to 5 times stronger than $\mathrm{He}$ II $\lambda 4686$, and the $\mathrm{N}$ III $\lambda 4640$ band should be marginally detected in many objects. O III and He II lines, at 374 and $304 \AA$, are the strongest predicted far-ultraviolet lines, with the intensity of the latter approaching that of $\mathrm{H} \mathrm{Ly} \alpha$. We study the He II $\lambda 1640 / \lambda 4686$ line ratio, taking into account the interaction of $\mathrm{He}^{+}$with the $\mathrm{H} \mathrm{Ly} \alpha$ radiation field. The process is found to be insignificant except for cases of large internal (microturbulent) motion, combined with extreme densities $\left(N_{e}>10^{10} \mathrm{~cm}{ }^{-3}\right)$ and/or ionization parameters. Our best estimate for AGN broad-line clouds is He II $\lambda 1640 / \lambda 4686 \approx 10$, although values as small as 7 cannot be excluded. This line ratio is a good reddening indicator.
\end{abstract}

Subject headings: galaxies: nuclei - radiation mechanisms

\section{INTRODUCTION}

Emission lines of ionized helium are among the most important diagnostic indicators in the spectrum of active galactic nuclei (AGNs) and other types of gaseous nebulae. They provide information about the spectral distribution of the ionizing radiation and are useful reddening indicators (Davidson and Netzer 1979 and references therein; Netzer and Davidson 1979; Shuder and MacAlpine 1979; MacAlpine 1981). Recombination theory predicts, very accurately, the intensities of He II lines for low-density nebulae, and excellent calculations (Brocklehurst 1971; Seaton 1978) are available for comparison with the observations. This may not apply to the broad-line clouds of AGNs where the high densities and the interaction with the $\mathrm{H}$ Ly $\alpha$ radiation field can affect the $\mathrm{He}^{+}$level population. Preliminary calculations by MacAlpine (1981) indicate that such effects are not very important, but other workers (Grandi 1983) have questioned these results, and there is certainly a need for further investigation of this problem.

Related to this is the excitation of the $\mathrm{O}$ III and $\mathrm{N}$ III Bowen lines, commonly observed in planetary nebulae. These lines are the results of wavelength coincidence and fluorescence of $\mathrm{He}$ II Ly $\alpha$, at $303.783 \AA$, with several resonance lines of $\mathrm{O}$ III. The process has been thoroughly investigated under planetary nebula conditions (Weymann and Williams 1969; Harrington 1972; Saraph and Seaton 1980; Kallman and McCray 1980) and in X-ray binaries (Kallman and McCray 1982; Deguchi 1985) and is fairly well understood. However, very little has

\footnotetext{
${ }^{1}$ On leave from School of Physics and Astronomy and the Wise Observatory, Tel-Aviv University.
}

been done, observationally and theoretically, regarding this process in AGNs. Weymann and Williams (1969) calculated two models for the low-density region of Seyfert galaxies, but no calculations are available for the high-density clouds. The lines are reported to have been seen in some AGNs (e.g., Weymann and Williams 1969; Netzer 1974; Baldwin 1975; Boksenberg and Penston 1976; Osterbrock 1981; Shuder and Osterbrock 1981; Wills, Netzer, and Wills 1985), but reliable line intensities are not yet available. The He II Ly $\alpha$ transfer and its influence on the nebular ionization is a related problem. Potentially this is a very important process (e.g., Netzer and Ferland 1984), but it has not been studied so far.

A new work by Eastman and MacAlpine (1985), in which they study several of these questions with application to AGNs, was sent to us after this paper had been submitted. Later we refer briefly to some of these results.

A common difficulty in the study of all of the abovementioned problems is the transfer of line radiation in the presence of an overlapping continuum. In the absence of such an overlap, the line transfer can be studied using the escape probability method, which is both fast and reasonably accurate. The line-continuum overlap problem until now has required more elaborate techniques, which make the computations rather difficult. In this paper we introduce a new formalism for handling this problem. This technique is a pure "escape probability method," involving only the solution of the (nonlinear) level population algebraic equations. We have incorporated the relevant expressions into existing photoionization codes which were utilized to investigate the general problem of ionization and excitation of $\mathrm{He}$ II, $\mathrm{O}$ III, and $\mathrm{N}$ III in 
gaseous nebulae, with particular attention to AGN conditions. We explain the method in $\S$ II and present in $\S$ III the new results for ionization and line intensities under a large range of physical conditions. In $\S$ IV we discuss the implication for models of AGNs and other gaseous nebulae.

\section{RADIATIVE TRANSFER CALCULATIONS}

\section{a) Method}

Scattering of the strongest He II line at $303.783 \AA$ (Ly $\alpha)$, may result in one of the following: (1) escape from the nebula; (2) ionization of neutral helium or hydrogen; and (3) absorption by $\mathrm{O}^{++}$(two possible lines at 303.799 and $303.693 \AA$ ). Absorption by $\mathrm{O}^{++}$may result in escape of several $\mathrm{O}$ III lines, such as the well-known Bowen lines at 3444,3429 , and $3133 \AA$, ionization of $\mathrm{H}^{0}$ or $\mathrm{He}^{0}$, or reabsorption by $\mathrm{He}^{+}$. The escape of Bowen-line photons can lead to the emission of $\mathrm{O}$ III 2374.436 , which can be absorbed by $\mathrm{N}$ III in its ground state. This can

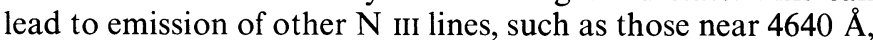
and further ionization of $\mathrm{H}^{0}$ and $\mathrm{He}^{0}$. We follow previous investigations and use the term "Bowen efficiency" to define the fraction of the created $\mathrm{He}$ II Ly $\alpha$ photons that are converted into $\mathrm{O}$ III Bowen lines. The term "fractional yield" is used in a similar way to describe all possible fates (i.e., 1, 2, or 3 above) of a created He II Ly $\alpha$ photon. More details of these processes can be found in Kallman and McCray (1980).

The relative strengths of the He II and Bowen lines depend on the ionization of the nebula, so both the ionization structure and the line-transfer problem have to be solved together. In the earlier works by Weymann and Williams (1969) and Kallman and McCray (1980) the two problems were solved separately. Such methods require further iterations, to correct the initial ionization structure for the results of the transfer calculations. This is necessary since the full line-transfer solution involves the diffusion of photons both in frequency and in space. Weymann and Williams (1969) and Harrington (1972) obtained accurate numerical solutions for the transfer of He II Ly $\alpha$, by using the Feautrier method and a precalculated ionization structure. No iteration was carried out, since they assumed that the effect of He II $\mathrm{Ly} \alpha$ on the ionization of the nebula was negligible. The similar and simplified method of Kallman and McCray (1980) for handling the radiative transfer is nearly as accurate and more efficient in terms of computing time.

As noted by Kallman and McCray, uncertainties in the ionization structure are usually large enough to become the dominant source of error. It is thus justifiable to sacrifice some precision in the transfer calculation for the sake of improving the ionization calculations. We agree with Kallman and McCray and present here a method that retains the necessary accuracy by solving simultaneously for the transfer and ionization equations at each point in the cloud. The numerical code used for the photoionization calculations is described elsewhere (Netzer and Ferland 1984 and references therein). It includes all the important physical processes, such as charge transfer, dielectronic recombination, ionization by secondary electrons, and transfer in lines of hydrogen, $\mathrm{Fe}$ II, $\mathrm{Mg}$ II, and $\mathrm{O}$. The interaction of $\mathrm{He}$ II $\mathrm{Ly} \alpha$ with $\mathrm{O}$ III, $\mathrm{H}^{0}$, and $\mathrm{He}^{0}$ and the fluorescence of $\mathrm{O}$ III $\lambda 374$ with $\mathrm{N}$ III $\lambda 374$ are calculated at every step and used to modify the ionization structure at that point. There is no interaction with neighboring points, and the line transfer is solved locally. The transfer method described below is based on the escape probability formalism. Such methods are used for solving the transfer of the hydrogen lines (Netzer 1975; Davidson and Netzer 1979; Collin-Souffrin et al. 1981; Kwan and Krolik 1981; Elitzur 1984) with a reasonable degree of accuracy. It is natural, therefore, to extend them to the case of line overlapping and fluorescence.

Figure 1 shows the $\mathrm{O}$ III and $\mathrm{N}$ III energy-level diagrams used in this work. This schematic representation is chosen in order to save computing time while retaining the necessary features of branching ratios, total energy, distribution in wavelength (to work out the ionization of $\mathrm{H}^{0}$ and $\mathrm{He}^{0}$ ), and optical depths in resonance lines. More details of the different levels involved can be found in Kallman and McCray (1980), Saraph and Seaton (1980), and Nussbaumer (1971). ${ }^{2}$ Following Kallman and McCray (1980), we do not include the line $\mathrm{O}$ III 2303.693 , which is not very important under most circumstances. This line becomes a significant sink for He II $\lambda 304$ photons only when internal motions (expansion, microturbulence) greatly exceed the sound speed. Even for these conditions it does not absorb more than about $20 \%$ of the photons absorbed in $\mathrm{O}$ III $\lambda 303.799$, as can be seen, for example, in the calculations of Deguchi (1985).

Elitzur and Netzer (1985) described an escape probability method for calculating line fluorescence for lines of different width, optical depth, and degree of line overlapping. The procedure assumes rectangular line profiles, which is a fair approximation for lines of large optical depth whose source function is constant across the profile. The procedure is extended here to take into account the more general case of two overlapping lines plus a continuous opacity source.

Consider a continuous opacity source and two lines, $a$ and $b$, with different widths $\Delta a$ and $\Delta b$, and partial overlapping. The line source functions $\left(\widetilde{S}_{a}, \widetilde{S}_{b}\right)$ are defined in Elitzur and Netzer's (1985) equation (8) (hereafter EN8; other equations in this work will be referred to similarly), and the normalized opacities $\left(X_{a}, X_{b}, X_{c}\right)$ and line-width functions $\left(f_{a}, f_{b}\right)$ are defined in Figure 2. Consider first the case of one line plus continuum. This is equivalent to the case of two lines, considered by Elitzur and Netzer (1985), where one line is very broad compared with the other one. Let us use a subscript $c$ for all quantities relating to the continuum (i.e., the very broad "line") and a subscript $l$ for the line. EN16 can be rewritten in the following way:

$$
\begin{aligned}
\frac{d n_{2, l}}{d t}=-A\{ & n_{2, l}\left[1-X_{l}\left(1-\beta_{l c}\right)\right] \\
& \left.\quad-X_{c} \tilde{S}_{c}\left(1-\beta_{l c}\right)\left(n_{1, l}-n_{2, l}\right)\right\},
\end{aligned}
$$

where we have taken $f_{l}=1$ and $n$ is the population per sublevel, i.e., $n=N / g$, where $g$ is the statistical weight. Note that

$$
1-X_{l}\left(1-\beta_{l c}\right)=X_{c}+X_{l} \beta_{l c}
$$

and that the continuum source function, $\tilde{S}_{c}$, is negligible in the case of photoionization $\left(\tilde{S}_{c}=1 /\left[b_{i} \exp (h v / k T)-1\right]\right.$, where $b_{i}$ is the continuum departure coefficient; see Elitzur 1984). In these equations $\beta_{l c}$ is the local escape probability calculated for the total, line and continuum, optical depth at the line frequency:

$$
\beta_{l c}=\beta\left(\tau_{l}+\tau_{c}\right)
$$

\footnotetext{
${ }^{2}$ A paper by Kastner and Bhatia (1984) containing new atomic data for $\mathrm{N}$ III appeared in press after all our calculations had been completed. The branching ratio for the $4640 \AA$ lines is 0.0079 , instead of the value 0.01 used by us. We have recalculated our standard model with the new data and found a negligible difference.
} 


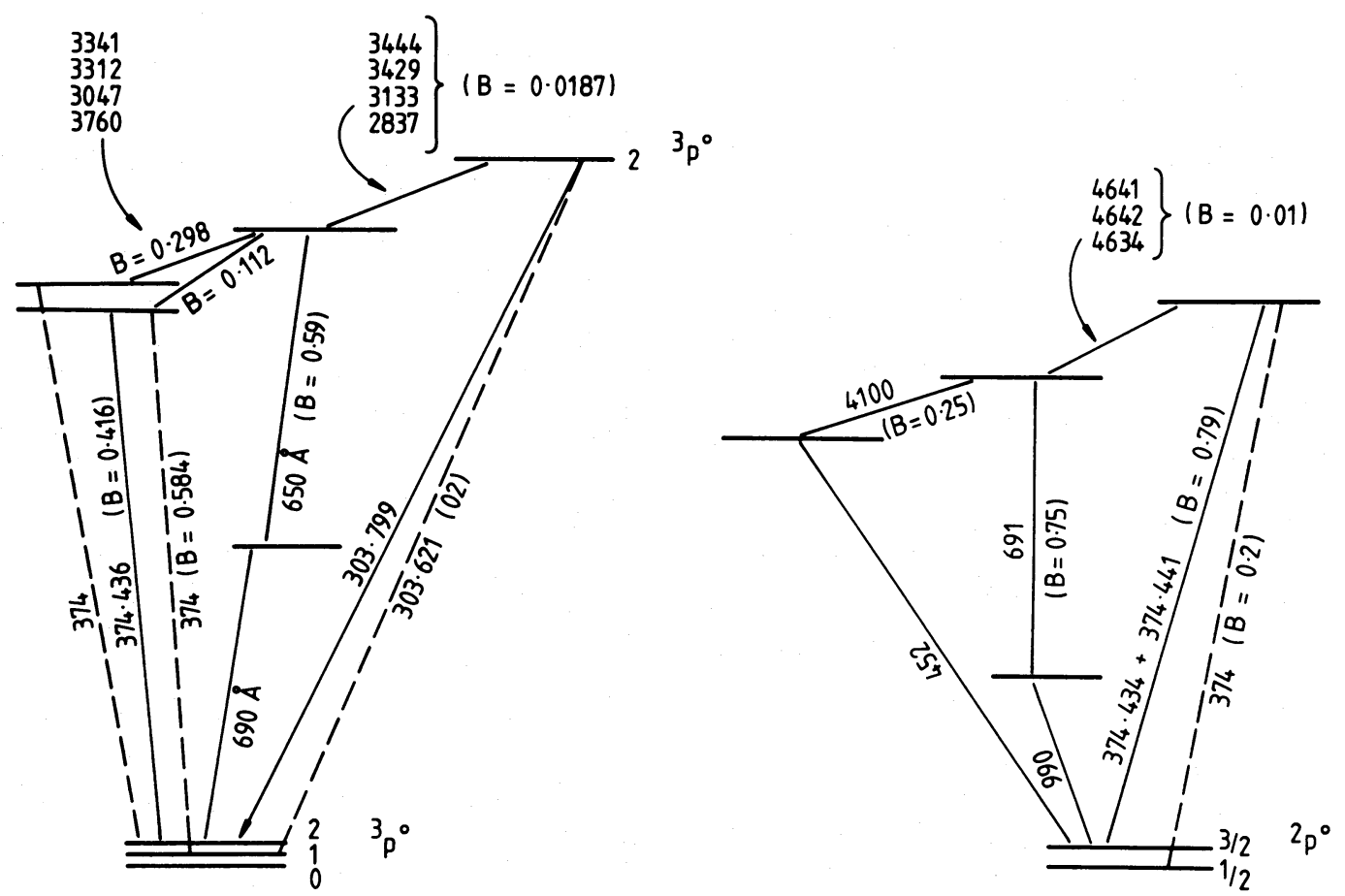

FIG. 1.-Energy-level diagram and branching ratios $(B)$ used in this work. The lines affected by fluorescence are $\mathrm{O}$ III $\lambda 303.799, \mathrm{O} \mathrm{III} \lambda 374.436$, and $\mathrm{N}$ III $\lambda \lambda 374.434,374.441$.

The line contribution to the emergent flux is

$$
F_{l}=A N_{2, l} \beta_{l c} \frac{h v}{4 \pi} \operatorname{ergs~} \mathrm{cm}^{-3} \mathrm{~s}^{-1} \mathrm{sr}^{-1}
$$

This case is therefore a simple generalization of the case of a single line with no continuum absorption, where the line escape probability, used for calculating the level population, is replaced by an effective escape probability given by

$$
\beta_{\text {eff }}=X_{c}+X_{l} \beta_{l c} .
$$

The results are identical with those obtained by Elitzur (1982) for the case of scattering by dust, with the local region replaced by the whole slab and $\beta(\tau)$ as defined in equation (2). Notice that this expression displays the two escape modes available: either by true escape or through absorption by the continuum. The number of ionizations (i.e., absorptions by the continuous opacity source) is

$$
F_{c}=A N_{2, l} X_{c}\left(1-\beta_{l c}\right) \mathrm{cm}^{-3} \mathrm{~s}^{-1} \text {. }
$$

Generalization to the case of two lines plus continuum is

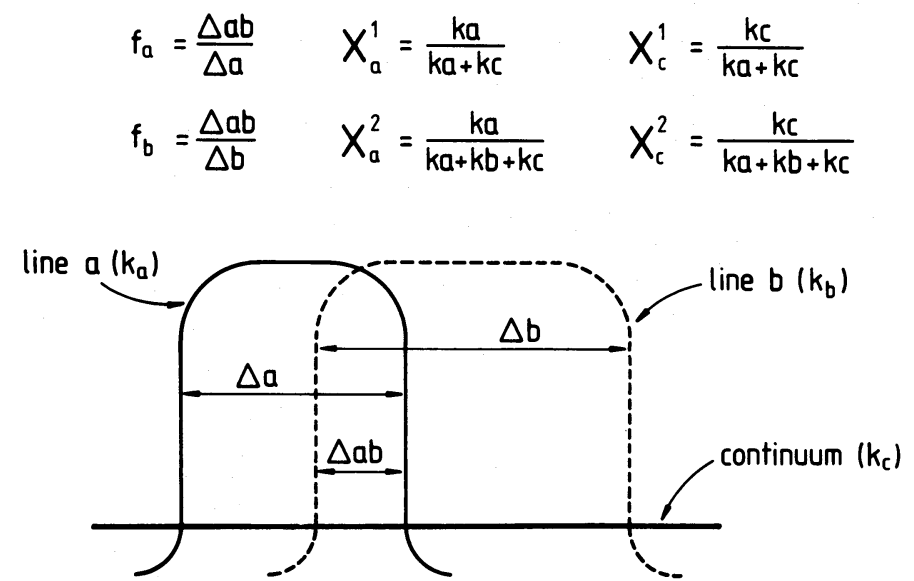

Fig. 2.-Definition of line overlapping parameters. The parameter $k$ is the absorption coefficient, i.e., $k_{a}=(h v / 4 \pi) g_{2} B_{21}\left(N_{1} / g_{1}-N_{2} / g_{2}\right) \phi(v)$, where $\phi(v)$ is the normalized line profile. In our case $=\phi(v)=1 / \Delta$ for all frequencies inside the profile, and $\phi(v)=0$ outside of it. Note that $X_{c}^{1, a}$ and $X_{c}^{1, b}$ in eq. (10) are the equivalent of $X_{c}^{1}$ here, for the appropriate line. 
straightforward. The equivalent of EN16 is now

$$
\begin{gathered}
\frac{d n_{2, a}}{d t}=-A_{a}\left\{n_{2, a}\left[1-X_{a}^{1}\left(1-f_{a}\right)\left(1-\beta_{a c}\right)-X_{a}^{2} f_{a}\left(1-\beta_{a b c}\right)\right]\right. \\
\left.-f_{a} X_{b}^{2} \widetilde{S}_{b}\left(1-\beta_{a b c}\right)\left(n_{1, a}-n_{2, a}\right)\right\}
\end{gathered}
$$

where we have dropped the term multiplying $\tilde{S}_{c}$. The equivalent of EN18, which is the equation needed to solve for the level population, is

$$
\begin{aligned}
\frac{d N_{2, a}}{d t}= & -A_{a} N_{2, a}\left[X_{c}^{1}+X_{a}^{1} \beta_{a c}+X_{a}^{1} f_{a}\left(1-\beta_{a c}\right)\right] \\
& +X_{a}^{2}\left(1-\beta_{a b c}\right)\left(f_{a} A_{a} N_{2, a}+f_{b} A_{b} N_{2, b}\right)
\end{aligned}
$$

The emergent flux in the line frequency is

$$
\begin{aligned}
& F_{l}=\left\{A_{a} N_{2, a}\left[\beta_{a c}\left(1-f_{a}\right)+\beta_{a b c} f_{a}\right]\right. \\
& \left.+A_{b} N_{2, b}\left[\beta_{b c}\left(1-f_{b}\right)+\beta_{a b c} f_{b}\right]\right\} \frac{h v}{4 \pi} \operatorname{ergs~cm}^{-3} \mathrm{~s}^{-1} \mathrm{sr}^{-1},
\end{aligned}
$$

and the total mumber of continuum absorptions is

$$
\begin{aligned}
F_{c}= & A_{a} N_{2, a}\left[X_{c}^{1, a}\left(1-\beta_{a c}\right)\left(1-f_{a}\right)\right] \\
& +A_{b} N_{2, b}\left[X_{c}^{1, b}\left(1-\beta_{b c}\right)\left(1-f_{b}\right)\right] \\
& +X_{c}^{2}\left(1-\beta_{a b c}\right)\left(A_{a} N_{2, a} f_{a}+A_{b} N_{2, b} f_{b}\right) \mathrm{cm}^{-3} \mathrm{~s}^{-1}
\end{aligned}
$$

It is easy to incorporate the above scheme into existing escape probability codes by separating equation (8) into an escape term multiplying the level population, $A_{a}\left[X_{c}^{1}+X_{a}^{1} \beta_{a c}\right.$ $\left.+X_{a}^{1} f_{a}\left(1-\beta_{a c}\right)-X_{a}^{2}\left(1-\beta_{a b c}\right) f_{a}\right]$ and a "pump" term, $X_{a}^{2}\left(1-\beta_{a b c}\right) f_{b} A_{b} N_{2, b}$ due to absorption of the other line photons.

As explained, all processes are assumed to take place locally. This is a good approximation considering the buildup of level population due to the scattering of line photons, since diffusion in space (in the wings) involves only a small number of scatterings. Continuum absorption is more complicated, since much of this can take place during the few scatterings that are associated with large diffusion in space ("nonlocal" absorption). See $\S$ II $b$ for evaluation of this uncertainty.

The assumption of rectangular line profiles is quite adequate, considering the constancy of the source function over the profile of an optically thick line (Adams 1972). Following Adams, we take the line half-width, $X_{*}$ (in units of Doppler width) to be

$$
X_{*}=\left(a \tau_{0} / \sqrt{ } \pi\right)^{1 / 3},
$$

where $a$ is the damping constant. This approximation applies over several orders of magnitude in optical depth (Adams 1972, Fig. 4). ${ }^{3}$

The above scheme was used to solve for the level population of $\mathrm{He}^{++}, \mathrm{O}^{++}$, and $\mathrm{N}^{++}$at each point. We consider a $\mathrm{He}^{+}$ atom with six levels plus continuum and complete angularmomentum distribution except for the $N=2$ level, where the populations of $2 p$ and $2 s$ are solved separately. To account for recombination into levels that are not included in the calculation $(N>6)$, we increase the individual recombination coefficients by density-dependent factors. This procedure preserves the density dependence of the effective recombination coefficients (Seaton 1968, 1978). The $\mathrm{O}^{++} 2 p 3 d^{3} P_{2}^{o}$ level (upper level of the $\mathrm{O}$ III $\lambda 303.799$ transition) is treated as an additional $\mathrm{He}^{+}$level. This removes the need for further iteration on the solution. The ground-level populations of $\mathrm{O}^{++}$and $\mathrm{N}^{++}$are solved explicitly at each point, allowing for accurate determination of the optical depth in the various transitions. The number of $\mathrm{H}^{0}$ and $\mathrm{He}^{0}$ ionizations (eq. [10]) is used for calculating the ionization of hydrogen and helium at that point.

\section{b) Comparison with Other Calculations}

Extensive tests have been carried out to check our method against the results of previous investigations. Table 1 and Figure 3 summarize these tests. As noted before, the ionization structure is important, and comparisons are meaningless unless it is the same. We duplicated the ionization structure of Weymann and Williams (1969) for the purpose of comparing our transfer calculation with theirs. The agreement with the Weymann and Williams Seyfert model (Table 1) is very good, and that with the planetary nebula model quite satisfactory (note that they do not list the $\mathrm{He}^{0}$ abundance in their models; this is very important in the planetary nebula case, and may be the reason for the slight disagreement). The comparison with the Kallman and McCray uniform model (Fig. 3) is again very satisfactory except in the very large $\tau(\operatorname{Ly} \alpha)$ region, where our method results in more continuum absorption. Kallman and McCray's (1980) method does not have the correct behavior at the very large $\tau(\mathrm{He}$ II $\mathrm{Ly} \alpha)$ limit, where they neglected to increase the effective bandwidths of the line (T. Kallman 1985, private communication). This explains the deviation seen in Figure 3.

\begin{tabular}{|c|c|c|c|c|}
\hline \multirow[b]{2}{*}{ LINES } & \multicolumn{2}{|c|}{ Planetary Nebula Model } & \multicolumn{2}{|c|}{ SEyfERT GaLAXY MOdEL } \\
\hline & WW & This Work & WW & This Work \\
\hline He II Ly $\alpha+O_{\text {III }} \lambda 303.799$ & 0.33 & 0.41 & 0.38 & 0.40 \\
\hline $\mathrm{O}_{\text {III }} \hat{\lambda} 303.621 \ldots \ldots \ldots \ldots \ldots \ldots$ & 0.08 & 0.11 & 0.11 & 0.07 \\
\hline Bowen conversion...$\ldots \ldots \ldots \ldots$ & 0.42 & 0.30 & 0.44 & 0.48 \\
\hline $\mathrm{H}^{0}, \mathrm{He}^{0}$ ionization $\ldots \ldots \ldots \ldots \ldots$ & 0.17 & 0.18 & 0.07 & 0.05 \\
\hline
\end{tabular}

\footnotetext{
${ }^{3}$ Equation (11) reproduces quite well the frequency over which the line source function is constant, as needed in our line-transfer method. Other types of calculations, such as line radiation pressure, require the integral under the source function, and a more accurate value for this is (Adams 1972, Fig. 4) $X_{*}=1.16\left(a \tau_{0}\right)^{1 / 3}$. The two expressions deviate by a constant factor of 1.4 ; thus the results for two overlapping lines are the same, whichever of them is used. Continuum absorption is somewhat more sensitive to this.
}

TABLE 1

Comparison With Weymann and Williams (1969): Fractional Yields 


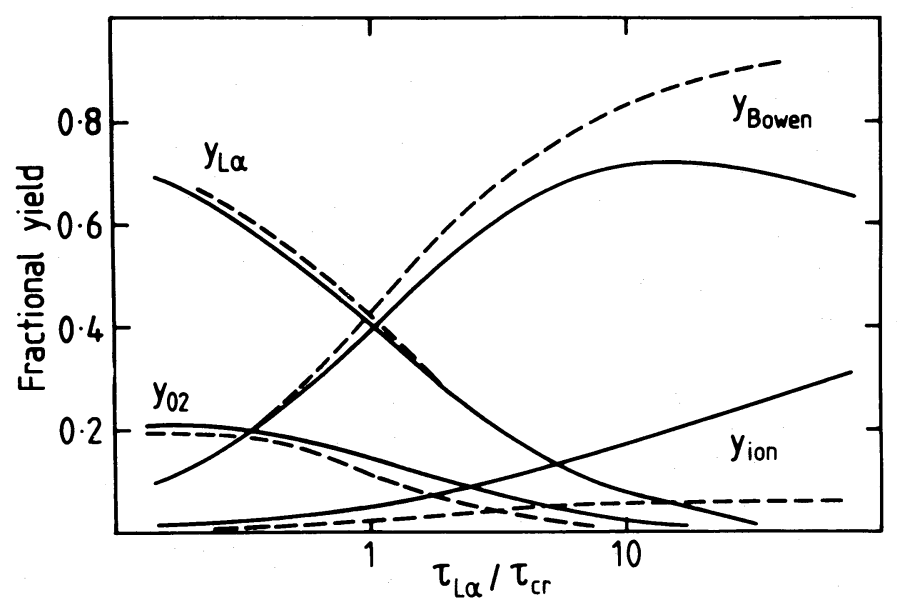

Fig. 3.-Fractional yields of different processes in a uniform slab model: a comparison with Kallman and McCray (1980). Solid line: this work; Dashed line: Kallman and McCray's Fig. 5. $Y_{02}$ represents escape in O III $\lambda 303.621$, and $Y_{\text {ion }}$ ionization of $\mathrm{H}^{0}$ and $\mathrm{He}^{0} ; \tau_{\mathrm{cr}}$ is the value of $\tau(\mathrm{He}$ II Ly $\alpha)$ for which the fraction escaping as He II Ly $\alpha$ and $\mathrm{O}$ III $\lambda 303.799$ photons, $\left(Y_{\mathrm{Ly} \alpha}\right)$, equals the fraction converted to Bowen line photons, $Y_{\text {Bowen }}$.

Recent calculations by Deguchi (1985) show similar behavior at all values of $\tau(\mathrm{He}$ II $\mathrm{Ly} \alpha)$. His calculations are for broadline profile (rotation, expansion) and include several transitions not considered by us. We did not carry out a detailed comparison but note the overall similarity in the general trend for small and large $\tau(\mathrm{He}$ II $\mathrm{Ly} \alpha)$.

Neither Kallman and McCray (1980) nor Weymann and Williams (1969) took into account the absorption of $\mathrm{O}$ III $\lambda 303.621$ photons by $\mathrm{H}^{0}$ and $\mathrm{He}^{0}$ and its effect on the $\mathrm{O}$ III level population. Our calculations are more accurate in this respect. Further tests, not shown here, show good agreement with the Kallman and McCray (1980) calculation of the $\mathrm{N}$ iII lines (their Fig. 8). Our simplified treatment for $\mathrm{N}$ III $\lambda 374$ (one line instead of two) gives the same results, within $20 \%$, as the more accurate treatment of Kallman and McCray (1980).

Recently Eastman and MacAlpine (1985) have combined photoionization calculation with a transfer method, similar to that of Weymann and Williams, to study the Bowen fluorescence in Seyfert galaxies and quasars. Unfortunately, we could not exactly duplicate the ionization structure in their standard model, and our Bowen efficiencies are different from theirs because of that.

We have tried to assess the accuracy of our line-pluscontinuum treatment, by comparison with published results. As explained, our transfer method is "local," with no influence of neighboring zones. Monte Carlo calculations, like those of Ferland and Netzer (1979) and Bonilha et al. (1979), produce only final results for the fractional destruction of photons, with no information on the influence on level population. The calculations of Hummer and Kunasz (1980) are different, since they provide both the change in the mean number of scatterings and the fractional increase of the mean path length. In our scheme the reduction in number of scatterings and the fraction of photons escaping are both given by $\beta_{l c} /\left(X_{c}+X_{l} \beta_{l c}\right)$, and this can be compared directly with the results in Hummer and Kunasz (1980 Table 2). We find very good agreement (usually better than a factor of 1.3) for both quantities over a large range in $\tau_{l}$, in those cases where $\tau_{c}<1$. The agreement for $\tau_{c} \gtrsim 1$ is good for the number of scatterings but poor for the fractional escape. Our method overestimates the fractional escape of photons, by up to a factor of about 5 , at this limit because it cannot take into account the large path traveled in the line wings. This uncertainty affects only the emergent flux in the lines but not the fractional destruction of photons (i.e., in our case the amount of $\mathrm{H}^{0}$ and $\mathrm{He}^{0}$ ionization), which is already close to $100 \%$ at this limit. One way to correct this is by introducing an extra $e^{-\tau_{c}}$ multiplication factor when calculating the emergent flux. This, however, is not a local treatment, and we consider the uncertainty as one of the principal limitations of our method.

\section{c) Interaction of $\mathrm{He}$ II with $\mathrm{H} \mathrm{Ly} \alpha$}

An additional prcess that must be considered is the influence of the $\mathrm{H} \mathrm{Ly} \alpha$ (mean wavelength $1215.67 \AA$ ) radiation field on the $\mathrm{He}^{+}$level population through interaction with its 2-4 transition (mean wavelength $1215.172 \AA$ ). The process is well known in O stars (Auer and Mihalas 1972 and references therein) and was first mentioned by Chan and Burbidge (1975) in relation to quasars. It is a potential source for enhancing the He II $\lambda 4686 / \lambda 1640$ line ratio by increasing the $\mathrm{He}^{+}$level 4 population. The simplified calculations of MacAlpine (1981) (now supported by Eastman and MacAlpine 1985) indicate that the process is not very important in AGN clouds, but there have been no detailed calculations yet.

We have considered three sources of $\mathrm{H}$ Ly $\alpha$ radiation: (1) local photons, i.e., $\mathrm{H} \mathrm{Ly} \alpha$ photons created in the same zone as the $\mathrm{He}^{+}$lines; (2) $\mathrm{H} \mathrm{Ly} \alpha$ from remote regions in the same cloud; and (3) $\mathrm{H} \mathrm{Ly} \alpha$ from other clouds. The last of these is unlikely to be of any significance in affecting the $\mathrm{He}^{+}$level population because of the large dilution and small covering factor (the radiation field due to $\mathrm{H} L y \alpha$ photons from other clouds is not much stronger than that of the continuum source at the same wavelength).

Process 1 can be calculated using the procedure outlined above or in Elitzur and Netzer (1985). We have performed these calculations, taking into account actual $\mathrm{H}^{0}$ and $\mathrm{He}^{+}$line widths at every point. It is easy to see that the process is of little importance for dynamically stable clouds (i.e., negligible turbulent or other internal motion). The separation of the lines, at a typical temperature of $20,000 \mathrm{~K}$, requires $\tau(\mathrm{H} \mathrm{Ly} \alpha)$ greater 
than $10^{6}$ for any line overlapping. Since the $\mathrm{He}^{++}$zone is usually smaller than the $\mathrm{H}^{+}$zone, the maximum $\tau(\mathrm{H} \mathrm{Ly} \alpha)$ expected is about $10^{4}$. Deeper in, where $\tau(\mathrm{H} \mathrm{Ly} \alpha)$ is larger, there is so little $\mathrm{He}^{++}$that the contribution to the flux in the lines is negligible. The situation may be different in cases of large internal motions that result in broader line profiles.

Process 2 was calculated assuming that the frequency of escaping photons is given by equation (11) (Adams 1972). The first iteration defines a mean $\mathrm{He}^{+} \mathrm{H} \beta$ profile and calculates the total number of $\mathrm{H} \mathrm{Ly} \alpha$ photons escaping in this frequency range over the entire cloud. A second iteration treats this as an external radiation source, assuming a slab geometry. The second iteration is necessary for this as well as for the determination of the total slab optical depth in several lines, used for determining the local escape probability.

Grandi (1983) has pointed out that the calculations of MacAlpine (1981) tend to underestimate the importance of this process, since H Ly $\alpha$ can be very broad in AGN clouds. This could only apply to process 2 above, since large $\tau(\mathrm{H} \mathrm{Ly} \alpha)$ regions are not associated with the $\mathrm{He}^{++}$zone. As will be seen later, contributions from remote regions are not very important either, mainly because of the narrow $\mathrm{He}$ II $\mathrm{H} \beta$ profile and the shift in frequency of the escaping H Ly $\alpha$ photons.

\section{RESULTS}

We have calculated several models considered typical of the broad and narrow-line regions of AGNs. These are "single cloud" models characterized by the gas density (or pressure) and abundances, the energy distribution of the ionizing continuum, and the ionization parameter. The ionizing continuum is given by

$$
F_{v}=a v^{-\alpha} \exp \left(-v / v_{\text {cutoff }}\right)+b v^{-0.7},
$$

where $a$ and $b$ are fluxes (ergs $\mathrm{s}^{-1} \mathrm{~Hz}^{-1}$ ) at the Lyman edge and $v$ is the frequency in rydbergs. The first term is the UV continuum flux, and the second represents the X-ray component with its typical flux distribution. The ratio $a / b$ is directly observed and is about 50 for radio-loud quasars and Seyfert 1 galaxies, and about 150 for radio-quiet objects (for further discussion of $a / b$ see Netzer 1985). The ionization parameter is defined here as

$$
U=\frac{a}{4 \pi R^{2} h N_{\mathrm{H}}} \mathrm{cm} \mathrm{s}^{-1} .
$$

Our standard case is a constant gas pressure model, with hydrogen density $N_{\mathrm{H}}$ at the illuminated face of the cloud of $10^{9.5} \mathrm{~cm}^{-3}$, and other abundances relative to hydrogen of $\mathrm{He}: \mathrm{O}: \mathrm{C}: \mathrm{N}: \mathrm{Ne}: \mathrm{Fe}: \mathrm{Mg}: \mathrm{S}: \mathrm{Si}=\left(10^{3}: 6.8: 3.7: 1.2: 1.1: 0.26\right.$ : $0.33: 0.16: 0.32) \times 10^{-4}$. The parameter values are $U=2.4 \times$ $10^{8} \mathrm{~cm} \mathrm{~s}^{-1}, \alpha=0.5, v_{\text {cutoff }}=15$ rydbergs, and $a / b=100$. The calculations stopped at $\tau(912 \AA)=10^{5}$ [this is of little significance, since the temperature drops below $6000 \mathrm{~K}$ at $\tau(912$ $\AA)=$ a few $\left.\times 10^{4}\right]$. Figure 4 shows the temperature and ionization structure in this model and the fractional yields of the most important processes following recombination to level 2 of $\mathrm{He}^{+}$.

The optical depth dependences of the different processes, shown in Figure 4, are very sensitive functions of the spectral distribution of the ionizing continuum. Steeper continuum results in less Bowen conversion, for the same value of the ionization parameter, mainly because of changes in the $\mathrm{He}^{++}$ $\mathrm{O}^{++}$abundance. The $\mathrm{O}$ III Bowen lines are thus very good

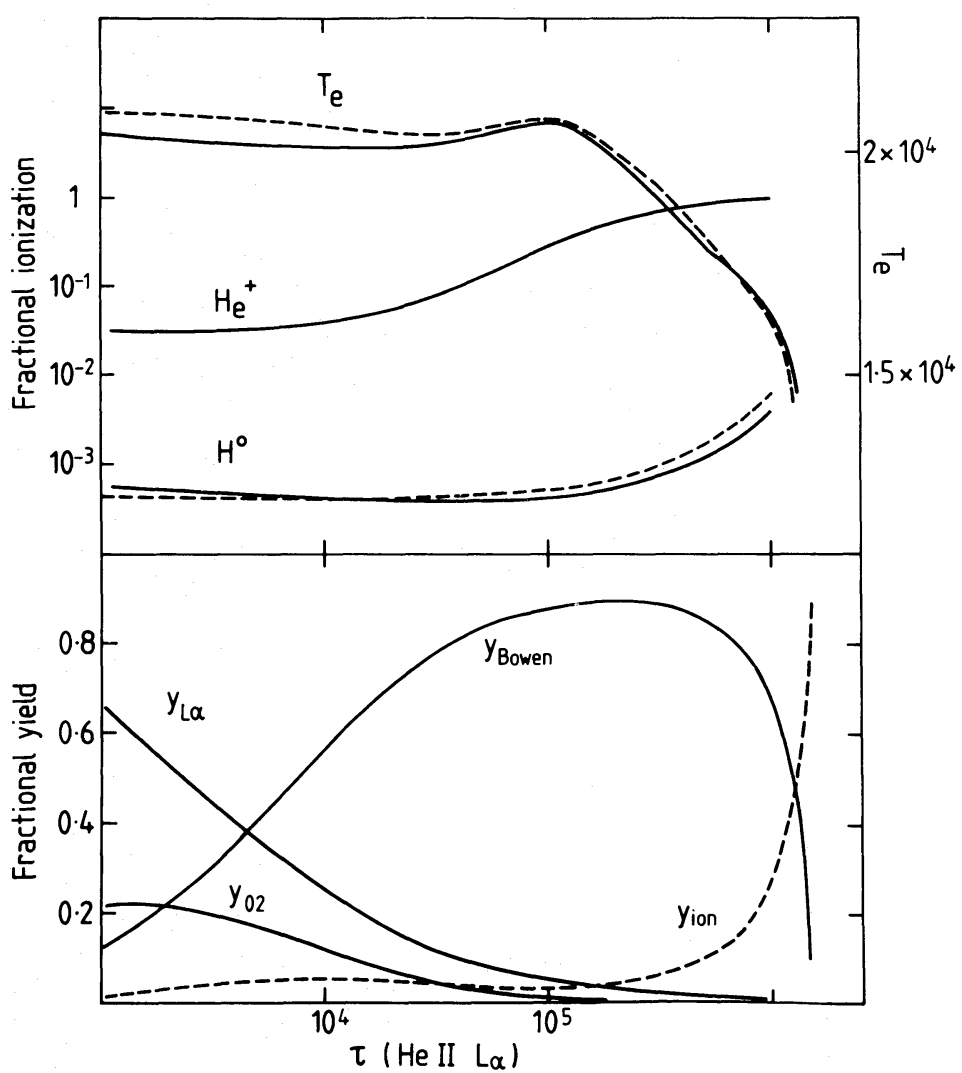

Fig. 4.-Lower panel: Fractional yields of the different processes following recombination to level 2 of $\mathrm{He}^{+}$, in the standard model. Symbols as in Fig. 3. Upper panel: Comparison of the new (this work, solid line) and the old (method of Netzer and Ferland 1984, dashed line) photoionization calculations. The fraction of $\mathrm{He}^{0}$ is negligble over the region shown.

indicators of the ultraviolet flux, and accurate determination of their relative intensity, compared with that of $\mathrm{He}$ II lines, can be of great significance (see line-ratio calculations below).

An important aspect of the present work is the improved calculation of the ionization and thermal structure at the $\mathrm{He}^{++}$zone. Previous calculations (Netzer and Ferland 1984 and references therein) used an approximate scheme to evaluate the number of $\mathrm{H}^{0}$ and $\mathrm{He}^{0}$ ionizations due to absorption of $\mathrm{He}$ II Ly $\alpha$ and other products of the Bowen mechanism. Such approximations may not be very accurate and may result in erroneous determinations of temperature and fractional abundances. An example is shown in Figure 4, where the temperature and ionization structure are compared with results obtained by the older method, as described in Netzer and Ferland (1984). Several other photoionization calculations that we are familiar with (e.g., Kwan and Krolik 1981) are using similar methods, and we expect similar deviations from the new solution. This is particularly important for constantpressure models, since the pressure is calculated with the values of $N_{e}$ and $T_{e}$ at the first (inner) zone. Figure 4 and other calculations that we have carried out suggest that the electron temperature calculated by the old method can be off by up to $10 \%$, as a result of uncertainties in the transfer of the $\mathrm{He}$ II and $\mathrm{O}$ III lines. Despite all this, we recommend the use of the Netzer and Ferland (1984) procedure when no other way is available, since it gives a good estimate for the total ionization of $\mathrm{H}^{0}$ and $\mathrm{He}^{0}$, at least for AGNs. 


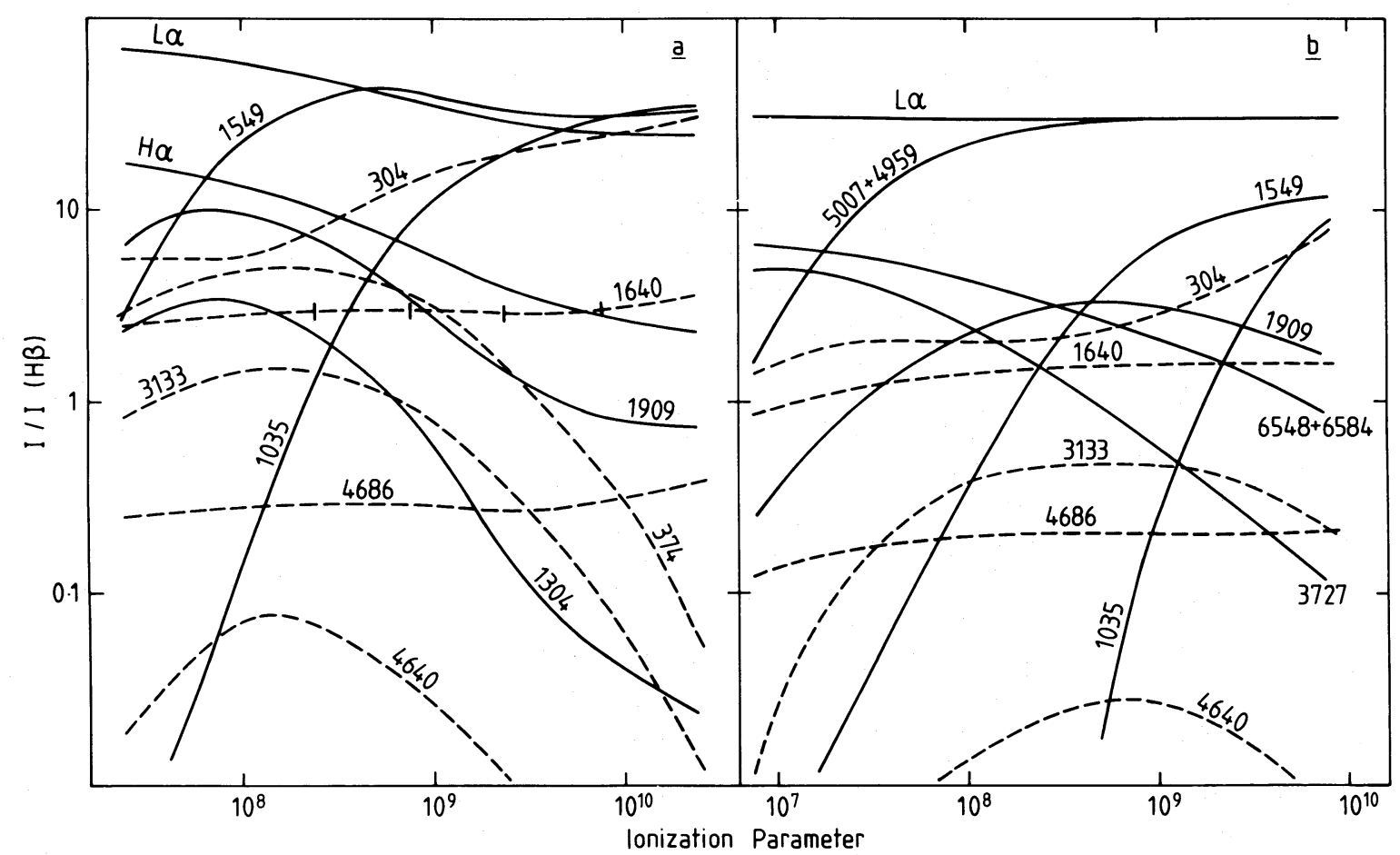

FIG. 5.-Relative line intensities in two constant gas pressure models. (a) Standard model $\left(\alpha=0.5, v_{\text {cutoff }}=15\right.$ rydbergs, $\left.N_{\mathbf{H}}=10^{9.5} \mathrm{~cm}^{-3}\right)(b)$ Low-density $\left(10^{4}\right.$ $\left.\mathrm{cm}^{-3}\right)$ steep continuum $(\alpha=1.5)$ model. The newly calculated lines of He II, O III, and N III are drawn with a dashed line. Tick marks on the He II $\lambda 1640$ curve give the line optical depth at (left to right) $0.07,0.5,3.4$, and 20.0. The $304 \AA$ line includes contributions from He II Ly $\alpha, \mathrm{O}$ III $\lambda 303.799$, and O III $\lambda 303.621$. Refer to Table 3 and the Appendix for the intensity of other emission lines.

We have studied the intensity of the He II, O III, and $\mathrm{N}$ III lines and their dependence on several parameters, such as heavy-element abundances, gas density, spectral index, and the ratio of the UV to X-ray flux $(a / b)$. Figure 5 demonstrates the dependence on ionization parameter for two UV continua: The models in Figure $5 a$ apply to the broad-line region of $\operatorname{AGNs}\left(N_{\mathrm{H}}=10^{9.5} \mathrm{~cm}^{-3}\right)$, while Figure $5 b$ is more appropriate for the narrow-line zone $\left(N_{\mathrm{H}}=10^{4} \mathrm{~cm}^{-3}\right)$. The different spectral indices are merely to illustrate more possibilities, and either of them can be applied in the narrow- or the broad-line regions. The difference between the two reflects the different degrees of ionization; thus models with steeper continuum $\left(v^{-1.5}\right)$ would give very similar results to those with flatter continua but somewhat smaller ionization parameter. Model parameters for several other cases are given in Table 2, and the corresponding intensities in Table 3. The combination of

TABLE 2

Parameters of Photolonization Models

\begin{tabular}{|c|c|c|c|c|c|}
\hline Model $^{a}$ & $\alpha$ & $\begin{array}{c}v_{\text {cutoff }} \\
\text { (rydbergs) }\end{array}$ & $\underset{\left(\mathrm{cm}^{-3}\right)}{N_{\mathrm{H}}}$ & Abundances & $a / b$ \\
\hline a & 0.5 & 15 & $10^{\circ .5}$ & cosmic & 100 \\
\hline $\mathrm{b}, \ldots \ldots \ldots+\ldots$ & -0.1 & 15 & $10^{9.5}$ & cosmic & 100 \\
\hline …..... & 1.5 & & $10^{9.5}$ & cosmic & 100 \\
\hline ........ & 0.5 & 15 & $10^{9.5}$ & $4 \times$ cosmic & 100 \\
\hline ............ & 0.5 & 15 & $10^{9.5}$ & $0.25 \times$ cosmic & 100 \\
\hline $\mathrm{f} \ldots \ldots \ldots \ldots \ldots \ldots$ & 0.5 & 15 & $10^{10.5}$ & cosmic & 100 \\
\hline$\ldots \ldots \ldots \ldots$ & 0.5 & 15 & $10^{7}$ & cosmic & 100 \\
\hline & 1.5 & $\cdots$ & $10^{4}$ & cosmic & 100 \\
\hline i $\ldots \ldots \ldots \ldots \ldots \ldots$ & 1.5 & $\ldots$ & $10^{9.5}$ & cosmic & 25 \\
\hline
\end{tabular}

${ }^{a}$ All are constant gas pressure models, with ionizing spectrum as defined in eq. (12); $\tau(912 \AA)=10^{5}$ and $U=2.4 \times 10^{8} \mathrm{~cm} \mathrm{~s}^{-1}$.
Figure 5 and Table 3 can be used to obtain the strength of most emission lines over the range $10^{7}-10^{10} \mathrm{~cm} \mathrm{~s}^{-1}$ in $U, 10^{4}-$ $10^{10.5} \mathrm{~cm}^{-3}$ in gas density, and -0.1 to 1.5 in UV spectral index. Intensities of other Bowen lines, compared with $\mathrm{O}$ III $\lambda 3133$ and $\mathrm{N}$ III $\lambda 4640$, are given in an appendix.

We have calculated several models corresponding to ionization by a thermal source. These have a different ionization structure and may be more applicable to objects such as planetary nebulae and novae. It is not practical to investigate the dependence on all possible parameters, so we have chosen to give an example of a medium-density $\left(N_{\mathrm{H}}=10^{7} \mathrm{~cm}^{-3}\right.$ at the illuminated face), single-ionization parameter $\left(U=2.4 \times 10^{8} \mathrm{~cm} \mathrm{~s}^{-1}\right)$ model. Figure 6 shows line intensities as a function of the ionizing radiation temperature for these models. A higher ionization parameter is somewhat equivalent, although not in a very simple way, to a higher ionizing temperature. None of these models should be directly applied to real planetary nebulae, since they do not include the geometrical dilution typical of such objects.

\section{DISCUSSION}

An interesting result of the present study is the extremely large intensities of the $\mathrm{O}$ III 23133 and the other $\mathrm{O}$ III Bowen lines. A typical ratio for planetaries is $I(\mathrm{O}$ III 23133$) /$ $I(\mathrm{He}$ II 24686$)=1.5$ (e.g., Saraph and Seaton 1980), while in our study this can exceed 5. This is due to the different ionization structure and gas density. The maximum theoretical ratio, assuming no collisional excitation of $\mathrm{He}$ II $\lambda 304$, is about 3.4 in the low-density limit and 7.6 in the high-density limit. (These values assume complete conversion of $\mathrm{He}$ II $\lambda 304$ photons into Bowen lines.) The typical Bowen efficiency, in most of our models, is between $50 \%$ and $70 \%$ (see Table 3 ). 
TABLE 3

A. InTENSities for Models Relative to $\mathrm{H} \beta$

\begin{tabular}{|c|c|c|c|c|c|c|c|c|c|}
\hline \multirow[b]{2}{*}{ LINES } & \multicolumn{9}{|c|}{ MODEL } \\
\hline & a & $\mathrm{b}$ & c & d & $\mathrm{e}$ & $\mathrm{f}$ & $\mathrm{g}$ & $\mathrm{h}$ & $\mathrm{i}$ \\
\hline $\mathrm{H} \beta, \ldots \ldots \ldots \ldots \ldots \ldots$ & 1 & 1 & 1 & 1 & 1 & 1 & 1 & 1 & 1 \\
\hline 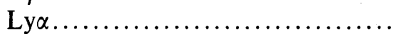 & 49 & 23 & 45 & 53 & 38 & 15 & 58 & 30 & 42 \\
\hline 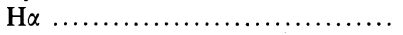 & 10.3 & 5.0 & 9.7 & 7.8 & 8.9 & 2.8 & 3.45 & 2.85 & 10.8 \\
\hline $\operatorname{Pa}(\ldots \ldots \ldots$ & 1.05 & 0.55 & 1.0 & 0.8 & 0.91 & 0.29 & 0.31 & 0.28 & 1.15 \\
\hline $\mathrm{He}_{1} \lambda 5876 \ldots \ldots \ldots \ldots \ldots \ldots \ldots \ldots$ & 0.18 & 0.04 & 0.24 & 0.23 & 0.10 & 0.65 & 0.11 & 0.12 & 0.18 \\
\hline He I $\lambda 1640 \ldots \ldots \ldots \ldots \ldots \ldots \ldots . . . \ldots . \ldots$ & 2.96 & 1.56 & 1.5 & 3.6 & 1.77 & 1.37 & 3.1 & 1.47 & 1.45 \\
\hline Не Іі $\lambda 4686 \ldots \ldots \ldots \ldots \ldots \ldots$ & 0.29 & 0.15 & 0.15 & 0.36 & 0.17 & 0.12 & 0.40 & 0.21 & 0.14 \\
\hline $\mathrm{He}$ II $+\mathrm{O}$ III $\lambda 304 \ldots$. & 7.8 & 6.5 & 3.5 & 5.0 & 8.3 & 3.5 & 8.1 & 2.1 & 3.3 \\
\hline $\mathrm{O}$ III $+\mathrm{N}_{\text {III }} \lambda 374 \ldots \ldots \ldots \ldots \ldots \ldots$ & 4.9 & 1.1 & 2.7 & 7.7 & 1.8 & 2.2 & 5.1 & 1.6 & 2.6 \\
\hline O III $\lambda 3133 \ldots \ldots \ldots \ldots \ldots \ldots \ldots$ & 1.38 & 0.38 & 0.74 & 2.1 & 0.50 & 0.63 & 1.5 & 0.45 & 0.72 \\
\hline $\mathrm{N}$ III $\lambda 4640 \ldots \ldots \ldots \ldots \ldots \ldots \ldots \ldots$ & 0.07 & 0.01 & 0.04 & 0.16 & 0.012 & 0.033 & 0.08 & 0.02 & 0.04 \\
\hline Civ $\lambda 1549 \ldots \ldots .$. & 36 & 16 & 12.8 & 64 & 12.5 & 19 & 31 & 1.5 & 13.9 \\
\hline $\mathrm{C}_{\text {IIII }} \lambda 1909 \ldots \ldots \ldots \ldots \ldots \ldots \ldots$ & 7.3 & 1.2 & 9.0 & 22 & 1.6 & 0.9 & 13.8 & 3 & 8.5 \\
\hline O VI $\lambda 1035 \ldots \ldots \ldots \ldots \ldots \ldots \ldots$ & 1.2 & 7.2 & 0.02 & 1.3 & 0.8 & 0.6 & 1.1 & & 0.03 \\
\hline $\left.\mathrm{O}_{\mathrm{III}}\right] \lambda 1663 \ldots \ldots \ldots \ldots \ldots \ldots \ldots \ldots$ & 3.3 & 1.0 & 2.7 & 7.7 & 0.9 & 1.3 & 3.1 & 0.35 & 2.7 \\
\hline $\mathrm{Mg}_{\mathrm{II}} \lambda 2798 \ldots \ldots \ldots \ldots \ldots \ldots \ldots \ldots \ldots \ldots \ldots \ldots$ & 2.6 & 1.0 & 5.2 & 7.0 & 0.7 & 1.2 & 2.3 & 1.2 & 5.4 \\
\hline Fe II (total) $\ldots \ldots \ldots \ldots \ldots \ldots \ldots \ldots$ & 4.5 & 2.0 & 6.8 & 20.1 & 1.0 & 1.2 & 6.0 & 3.9 & 7.6 \\
\hline $\left.\mathrm{N}_{\text {III }}\right] \lambda 1750 \ldots \ldots \ldots \ldots \ldots \ldots \ldots \ldots \ldots$ & 1.3 & 0.3 & 1.3 & 3.4 & 0.3 & 0.4 & 1.5 & 0.2 & 1.3 \\
\hline O $121304 \ldots \ldots \ldots \ldots \ldots \ldots \ldots \ldots$ & 2.2 & 1.6 & 2.1 & 8.1 & 0.76 & 0.18 & 0.01 & $\ldots$ & 2.8 \\
\hline$[\mathrm{O} \mathrm{III}] \lambda \lambda 5007,4959 \ldots \ldots \ldots \ldots \ldots$ & $\ldots$ & $\ldots$ & $\ldots$ & 0.04 & $\ldots$ & $\ldots$ & 3.0 & 27 & $\ldots$ \\
\hline$[\mathrm{O}$ II $] \lambda 3727 \ldots \ldots \ldots \ldots \ldots \ldots \ldots \ldots \ldots \ldots \ldots \ldots$ & $\ldots$ & $\ldots$ & $\ldots$ & & $\ldots$ & $\ldots$ & & 1.5 & $\ldots$ \\
\hline$\left.\left[\mathrm{O}_{1}\right]\right] \lambda \lambda 6300,6364 \ldots \ldots \ldots \ldots \ldots$ & $\ldots$ & $\ldots$ & $\ldots$ & 0.03 & $\ldots$ & $\ldots$ & 0.9 & 1.4 & $\ldots$ \\
\hline$\left[\mathrm{N}_{\mathrm{II}}\right] \lambda \lambda 6548,6584 \ldots \ldots \ldots \ldots \ldots \ldots$ & $\ldots$ & $\ldots$ & $\ldots$ & $\ldots$ & $\ldots$ & $\ldots$ & 0.1 & 3.4 & $\ldots$ \\
\hline$[\mathrm{Ne}$ III $] \lambda \lambda 38699,3897 \ldots \ldots \ldots \ldots \ldots$ & $\ldots$ & $\ldots$ & $\ldots$ & $\ldots$ & $\ldots$ & $\ldots$ & 1.5 & 1.5 & $\ldots$ \\
\hline$[\mathrm{Ne} \mathrm{v}] \lambda \lambda 3426,3346 \ldots \ldots \ldots \ldots \ldots$ & $\ldots$ & $\ldots$ & $\ldots$ & $\ldots$ & $\ldots$ & $\ldots$ & 1.4 & 0.4 & $\ldots$ \\
\hline 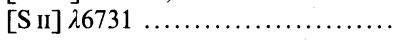 & $\ldots$ & $\ldots$ & $\ldots$ & $\ldots$ & $\ldots$ & $\ldots$ & $\ldots$ & 0.6 & $\ldots$ \\
\hline
\end{tabular}

B. Fractional YieldS

\begin{tabular}{|c|c|c|c|c|c|c|c|c|c|}
\hline \multirow[b]{2}{*}{ LINES } & \multicolumn{9}{|c|}{ MODEL } \\
\hline & $\mathrm{a}$ & $\mathrm{b}$ & c & $\mathrm{d}$ & $\mathrm{e}$ & f & $\mathrm{g}$ & $\mathrm{h}$ & $\mathrm{i}$ \\
\hline He II Ly $\alpha+$ O III $\lambda 303.799$. & 0.18 & 0.30 & 0.16 & 0.09 & 0.33 & 0.18 & 0.17 & 0.17 & 0.16 \\
\hline $\mathrm{O}_{\mathrm{III}} \lambda 303.621 \ldots \ldots \ldots \ldots \ldots \ldots \ldots$ & 0.07 & 0.11 & 0.07 & 0.04 & 0.11 & 0.07 & 0.07 & 0.05 & 0.06 \\
\hline Bowen lines ...................... & 0.69 & 0.36 & 0.72 & 0.85 & 0.42 & 0.70 & 0.70 & 0.70 & 0.73 \\
\hline $\mathbf{H}^{0}, \mathrm{He}^{0}$ ionization $\ldots \ldots \ldots \ldots \ldots \ldots$ & 0.06 & 0.23 & 0.05 & 0.02 & 0.14 & 0.05 & 0.06 & 0.08 & 0.05 \\
\hline
\end{tabular}

\begin{tabular}{|c|c|c|c|c|c|c|c|c|c|}
\hline \multirow[b]{2}{*}{ LiNES } & \multicolumn{9}{|c|}{ MODEL } \\
\hline & a & $\mathrm{b}$ & c & d & $\mathrm{e}$ & $f$ & $\mathrm{~g}$ & $\mathrm{~h}$ & $\mathrm{i}$ \\
\hline $\mathrm{He}_{\text {II }} \mathrm{Ly} \alpha .$. & $1.9 \times 10^{6}$ & $2.4 \times 10^{6}$ & $1.4 \times 10^{6}$ & $1.5 \times 10^{6}$ & $2.0 \times 10^{3}$ & $3.9 \times 10^{6}$ & $1.9 \times 10^{6}$ & $1.2 \times 10^{6}$ & $1.4 \times 10^{6}$ \\
\hline $\mathrm{H} \alpha \ldots \ldots$ & $6.2 \times 10^{3}$ & $1.1 \times 10^{4}$ & $4.4 \times 10^{3}$ & $2.8 \times 10^{3}$ & $9.6 \times 10^{3}$ & $4.3 \times 10^{3}$ & 71 & 0.03 & $6.1 \times 10^{3}$ \\
\hline $\mathrm{HPa} \alpha$. & $1.5 \times 10^{2}$ & $8.5 \times 10^{2}$ & 57 & 24 & $3.6 \times 10^{2}$ & $4.8 \times 10^{2}$ & $\ldots$ & $\ldots$ & $1.2 \times 10^{2}$ \\
\hline He II $\lambda 1640$.. & 0.07 & 0.55 & 0.22 & 0.015 & 0.2 & 0.8 & & & $n \cap)$ \\
\hline $\mathrm{H} \beta$ flux $\left(\mathrm{ergs} \mathrm{s}^{-1} \mathrm{~cm}^{-2}\right)$ & $4.3 \times 10^{5}$ & $3.0 \times 10^{6}$ & $2.1 \times 10^{5}$ & $2.5 \times 10^{5}$ & $8.3 \times 10^{5}$ & $9.9 \times 10^{6}$ & $1.2 \times 10^{3}$ & 0.7 & $2.5 \times 10^{5}$ \\
\hline
\end{tabular}

Similarly, the maximum theoretical intensity ratio of I $(\mathrm{N}$ III $\lambda 4640) / I(\mathrm{He}$ II 24686$)$ is about 0.4 in the low-density limit and 0.85 in the high-density limit. The maximum line ratio in Figure 5 is $35 \%$ of this value. The $\mathrm{O}$ III and the $\mathrm{N}$ III Bowen lines are weaker at large ionization parameters, since oxygen and nitrogen are more than doubly ionized in the $\mathrm{He}^{++}$zone. The lines are also weak at low ionization parameters, because of the enhanced $\mathrm{H}^{0} / \mathrm{H}^{+}$ratio and the high efficiency of continuum absorption. This demonstrates the importance of accurate ionization calculations in determining the strength of the Bowen lines.

Most of the dependences on model parameters, as shown in
Figures 5 and 6 and in Table 3, are self-explained. One of the most significant is on the $\mathrm{N}$ and $\mathrm{O}$ abundances. High abundances (model d) produce more Bowen lines and fewer $304 \AA$ photons, as well as intense $\mathrm{N}$ III $\lambda 4640$, because of the larger optical depth in the $\mathrm{O}$ III and $\mathrm{N}$ III resonance lines. The opposite is true for low abundances (model e). As already mentioned, it is impossible to determine the dependence on $U$ and $\alpha$ separately, using the $\mathrm{O}$ III and $\mathrm{N}$ III lines, since a flatter continuum is more or less equivalent to a larger value of $U$.

Figure 5 and Table 3 confirm our earlier suggestion that the He II $\lambda 4686 / \lambda 1640$ line ratio is approximately constant over a large range of conditions. This is especially interesting in the 


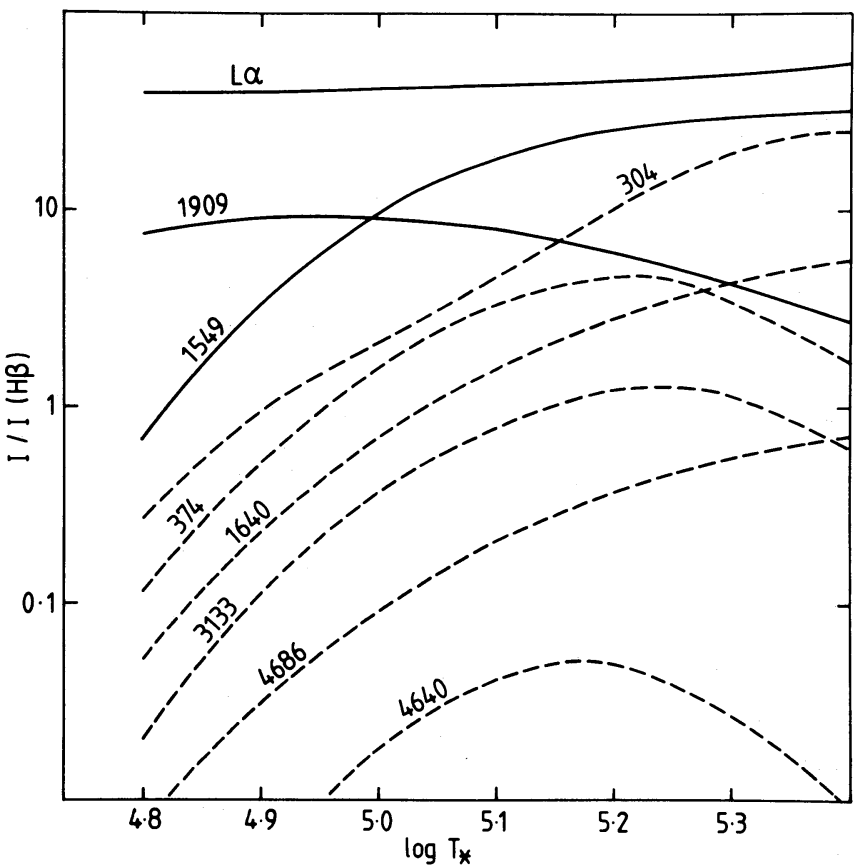

FIG. 6.- Relative line intensities for a constant gas pressure model with a blackbody ionizing source of temperature $T_{*}$. $N_{\mathrm{H}}=10^{7} \mathrm{~cm}^{-3}$, and $U=2.4 \times 10^{8} \mathrm{~cm} \mathrm{~s}^{-1}$.

high ionization parameter limit of Figure $5 a$, where the optical depth in He II $\lambda 1640$ is significant (more than 20 for $U=10^{10}$ ). It results in some increase in both lines (like the small optical depth limit in the hydrogen Balmer and Paschen lines; see Netzer 1975), while the line ratio remains basically unchanged. Note, however, that $\tau(\mathrm{He}$ II 21640$)$ is not a simple function of the ionization parameter but depends more directly on the 4 rydberg ionizing flux. (It depends on the ionization parameter, since this defines $\tau(\mathrm{He}$ II $\mathrm{Ly} \alpha)$ and the Bowen efficiency.) The best line ratio to use for broad-line clouds is about 10 , while for low densities Seaton's (1978) tabulation is recommended.

We have investigated conditions that are likely to increase the interaction of the $\mathrm{H} \mathrm{Ly} \alpha$ radiation field with $\mathrm{He}^{+}$. As explained, this requires broader lines in the $\mathrm{He}^{++}$zone, so that the $\mathrm{H} \mathrm{Ly} \alpha$ and the $\mathrm{He}$ II $\mathrm{H} \beta$ overlap. One way to induce this effect is with internal motions, such as microturbulences. Figure 7 shows the $\mathrm{He}$ II $\lambda 1640 / \lambda 4686$ line ratio as a function of the internal microturbulent velocity, $V_{\text {turb }}$, for several broadline models.

The decrease in He II $\lambda 1640 / \lambda 4686$ is almost entirely due to the enhanced emission of He II $\lambda 4686$, as can be seen in the top part of the diagram. The process is significant when the $\mathrm{H} \mathrm{Ly} \alpha$ line is broad enough to engulf the $\mathrm{He}$ II $\mathrm{H} \beta$ profile. This occurs for $V_{\text {turb }} \gtrsim 25 \mathrm{~km} \mathrm{~s}^{-1}$. The calculations show that the He II $\lambda 4686$ enhancement is due partly to local pumping (process 1 in $\S$ II) and partly to $\mathrm{H} \mathrm{Ly} \alpha$ photons from deeper parts of the cloud (process 2 above). It requires a large population of $N=2 \mathrm{He}^{+}$atoms [i.e., large $\tau(1640)$ ] to compete with absorption of $\mathrm{H} \mathrm{Ly} \alpha$ by neutral hydrogen. Most favorable conditions are in large- $U$ and/or large-density clouds, where the strong ionizing flux results in a considerable value of $\tau(1640)$. The reason for the rise back of He II $\lambda 1640 / \lambda 4686$ at large $V_{\text {turb }}$ is the decrease in the optical depth of He II $\lambda 1640$ [to a first approximation $\left.\tau(1640) \propto\left(V_{\text {turb }}+V_{\text {therm }}\right)^{2} / V_{\text {therm }}^{2}\right]$. The magnitude of the change in the $\mathrm{He}$ II line ratio is roughly pro- portional to the ionizing flux at $v=4$ rydbergs, and it is easy to scale it to cases of different spectral indices. The large $V_{\text {turb }}$ model results also in more $\mathrm{O}$ III $\lambda 303.621$ escape and less Bowen conversion, as suggested by Weymann and Williams (1969).

We consider the conditions required for a significant enhancement of $\mathrm{He}$ II $\lambda 4686$ most unlikely. The high ionization parameter $\left(U \geq 10^{9}\right)$ results in line ratios that are not consistent with the observations. For example, Figure 7 curve $a\left(U=3 \times 10^{9}, \mathrm{~N}_{\mathrm{H}}=10^{9.5}\right)$, with $V_{\text {turb }}=45 \mathrm{~km} \mathrm{~s}^{-1}$, gives $\mathrm{He}$ II $\lambda 4686 / \mathrm{H} \mathrm{H} \beta \approx 1$, He II $\lambda 4686 / \lambda 3203 \approx 5$, and $\mathrm{C}$ IV $\lambda 1549 / \mathrm{H}$ Ly $\alpha \approx 1.1$. The high-density lower $U$ models have similar problems and other drawbacks, such as an extremely strong $\mathrm{He}_{\mathrm{I}} \lambda 5876$. A possibility that must be considered is a multiple-component atmosphere, with a large range in density and ionization parameter. This has been discussed in several places (Wills, Netzer, and Wills 1985 and references therein), but the high-density component is usually required to explain the strong low-excitation lines, mainly of $\mathrm{Fe}$ II, rather than the high-excitation ones like those of $\mathrm{He}$ II. As mentioned by many others before (e.g., Davidson and Netzer 1979), a large fraction of the line-emitting gas must have den-

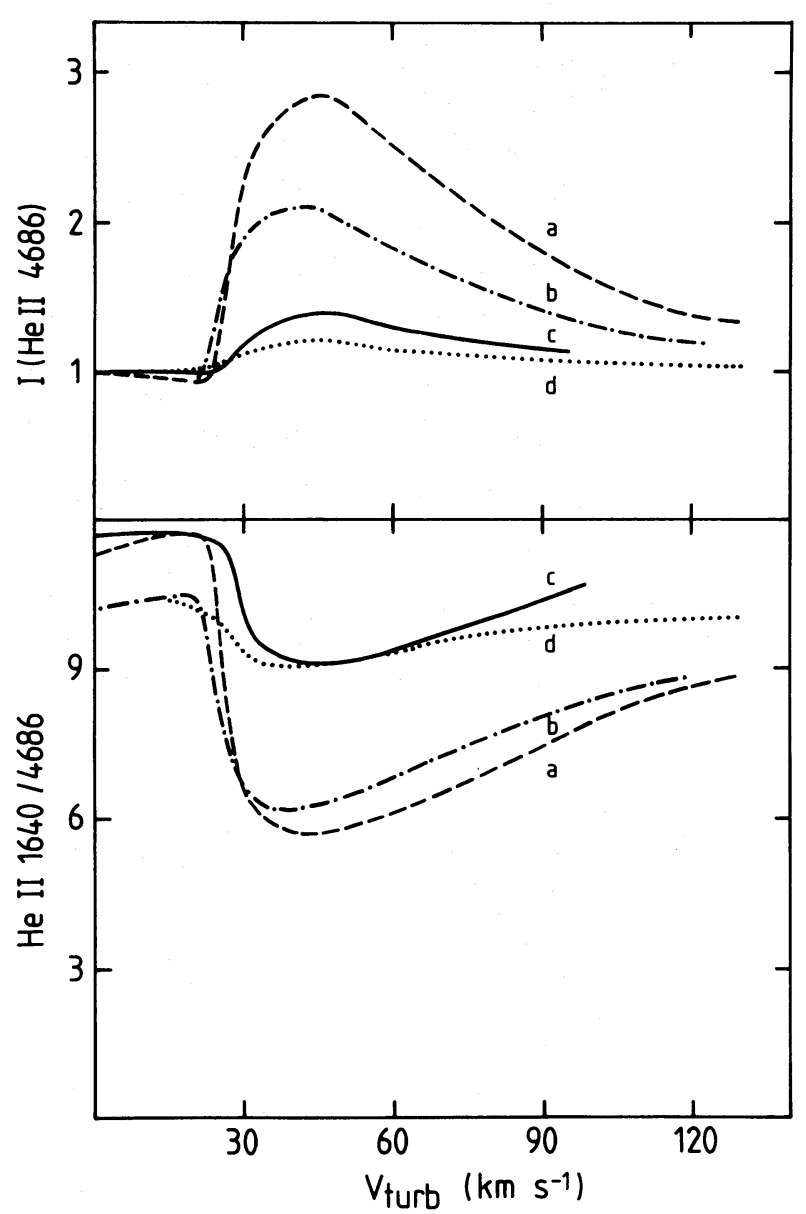

FIG. 7.- - He II line intensities as a function of the microturbulent velocity, $V_{\text {turb }}$, for a $F_{v} \propto v^{-0.5} \exp (-v / 15$ rydbergs) ionizing continuum. lower panel: He II $\lambda 1640 / \lambda 4686$. Upper panel: intensity of He II $\lambda 4686$ in units of its intensity for $V_{\text {turb }}=0$. Cases shown by labeled curves are $(a) U=10^{9}, N_{\mathrm{H}}=10^{10.5}$; (b) $U=3 \times 10^{9}, N_{\mathrm{H}}=10^{9.5} ;$ (c) $U=3 \times 10^{8}, N_{\mathrm{H}}=10^{10.5} ;$ (d) $U=10^{9}$, $N_{\mathrm{H}}=10^{9.5}$. 
sities considerably smaller than $10^{10} \mathrm{~cm}^{-3}$, to explain the observed intensity of several intercombination lines. Cloud stability is an additional, perhaps more severe, problem. It is not clear how the large internal velocities would originate, and how long such clouds would last. He II line ratios are very important reddening indicators (Netzer and Davidson 1979); Shuder and MacAlpine 1979; MacAlpine 1981). We suggest that they can safely be used for this purpose with a best theoretical ratio, for broad-line clouds, of He II $\lambda 1640 / \lambda 4686=10$. However, we cannot exclude line ratios as small as 7 or 8 , if some microturbulence did exist. The observational evidence regarding these lines is inconclusive, owing to the difficulties in measuring such weak spectral features.

There are several other implications for the study of AGNs. Observations with the Space Telescope may be able to detect the lines at 304 and $374 \AA$ in the spectrum of high-redshift quasars. These are the strongest far-UV lines expected and can range in intensity from $10 \%$ to $100 \%$ of the intensity of $\mathrm{H} \mathrm{Ly} \alpha$, depending on the ionization parameter. There is, however, a fundamental problem concerning the detection of such highenergy lines (see Netzer 1985). The near-UV Bowen lines could certainly be observed from space and from the ground. The $\mathrm{O}$ III $\lambda 3133$ line is predicted to be the strongest, with an intensity several times that of He II $\lambda 4686$ (a more direct comparison is with $\mathrm{He}$ II $\lambda 3203$, which typically has $50 \%$ of the intensity of $\mathrm{He}$ II 24686 ). Unfortunately this spectral range is full of strong $\mathrm{Fe}$ II lines which will make any accurate determination of the line strength very difficult. The combined intensity of the $\mathrm{N}$ III lines near $4640 \AA$ could add up to $25 \%$ of the intensity of $\mathrm{He}$ II 24686 . Modeling of the $4000-5000 \AA$ emission spectrum, as in the work of Wills, Netzer, and Wills (1985), may detect the presence of these lines in some objects. Narrow emission lines in Seyfert 1 and Seyfert 2 galaxies offer the best opportunity to observe all these transitions, since they are not confused with the hundreds of broad Fe II lines, common in the broad-line spectrum.

\section{CONCLUSIONS}

We have developed a new method to calculate the Bowen fluorescence mechanism and the transfer of $\mathrm{He}$ II lines. The procedure is shown to be quite accurate and yet simple enough to incorporate into general photoionization escape probability codes. We employ it to improve the calculations of temperature and ionization structure and to study the excitation of $\mathrm{He}$ II, $\mathrm{O}$ III, and $\mathrm{N}$ III lines under a variety of astrophysically interesting situations. We predict the detection of a strong $\mathrm{O}$ III $\lambda 3133$ line in many Seyfert galaxies and quasars, and calculate the intensity of $\mathrm{N}$ III $\lambda 4640$ and the far-UV lines of $\mathrm{He}$ II and $\mathrm{O}$ III at 304 and $374 \AA$. These lines depend on the ionization structure (i.e., the ionization parameter and the continuum spectral index) and the heavy-element abundances, and their detection may give some clues to the values of these parameters in AGN clouds. The He II $\lambda 1640 / \lambda 4686$ line ratio is calculated to be constant under a large range of conditions. This line ratio can, however, be considerably reduced under conditions of large internal motion combined with high density and large ionization parameter. Despite this, we think that it is a good reddening indicator.

A Royal Society Guest Research Fellowship to H. N. is gratefully acknowledged, along with the support of the National Science Foundation through grants AST 83-05094 (G. J. F.) and AST 83-04895 (M. E.).

\section{APPENDIX}

\section{RELATIVE INTENSITY OF O III AND $\mathrm{N}$ III BOWEN LINES}

\section{I. $\mathrm{O}$ III}

The intensities of many Bowen O III lines relative to O III $\lambda 3133$ are given in Saraph and Seaton (1980) and copied here (Table 4) for convenience. We assumed excitation due to $\mathrm{O}$ III $\lambda 303.799$ only and no collisional mixing of the $2 p 3 d$ and $2 p 3 p$ O III levels. Both assumptions are very good for all models shown in Figures 5 and 6 and in Table 3.

Note that photons with $\lambda<912 \AA$ can be absorbed by $\mathrm{H}^{0}$, most effectively those of the resonance lines (508, 703, and $835 \AA$ ). The numbers in the table do not induce this process and give, therefore, only an upper limit to the line density.

TABLE 4

INTENSITIES OF O III BOWEN LINES ReLATIVE TO O III $\lambda 3133$

\begin{tabular}{|c|c|c|c|}
\hline $\begin{array}{c}\text { Line } \\
(\AA)\end{array}$ & $\begin{array}{l}\text { Relative } \\
\text { Intensity }\end{array}$ & $\begin{array}{l}\text { Line } \\
(\AA)\end{array}$ & $\begin{array}{l}\text { Relative } \\
\text { Intensity }\end{array}$ \\
\hline $3133 \ldots$ & 1.000 & $3312 \ldots$ & 0.082 \\
\hline $3444 \ldots$ & 0.277 & $3299 \ldots$ & 0.028 \\
\hline $3429 \ldots$ & 0.093 & $3760 \ldots$ & 0.037 \\
\hline $2837 \ldots$ & 0.104 & $3791 \ldots$ & 0.002 \\
\hline $2819 \ldots$ & 0.019 & $3755 \ldots$ & 0.005 \\
\hline $2809 \ldots$ & 0.001 & $644 \ldots$ & 3.58 \\
\hline $3047 \ldots$ & 0.179 & $660 \ldots$ & 0.19 \\
\hline $3023 \ldots$ & 0.060 & $703 \ldots$ & 3.6 \\
\hline $3059 \ldots$ & 0.033 & (n....... & 0.36 \\
\hline $3035 \ldots$ & 0.020 & $835 \ldots$ & 0.33 \\
\hline $3025 \ldots$ & 0.027 & $633 \ldots$ & 0.15 \\
\hline $3341 \ldots \ldots \ldots \ldots \ldots \ldots$ & 0.136 & $508 \ldots \ldots \ldots \ldots \ldots$ & 0.01 \\
\hline
\end{tabular}


II. $\mathrm{N}$ III

The $\mathrm{N}$ III $\lambda 4640$ lines referred to in this work include the following: $\lambda \lambda 4640.64,4641.96,4634.17,2714.75,2715.19$, and 2714.88 . The relative intensities of these lines are given in Table 5, assuming equal excitation (by absorption of $\mathrm{O}$ III $\lambda 374.436$ ) of the two $3 d^{2} D \mathrm{~N}$ III sublevels, and using $A$-values given by Nussbaumer (1971). No collisional mixing is assumed.

TABLE 5

INTENSITIES OF N III BOWEN LiNes Relative to N III $\lambda 4640$

\begin{tabular}{|c|c|c|c|}
\hline $\begin{array}{l}\text { Line } \\
(\AA)\end{array}$ & $\begin{array}{l}\text { Relative } \\
\text { Intensity }\end{array}$ & $\begin{array}{c}\text { Line } \\
(\AA)\end{array}$ & $\begin{array}{l}\text { Relative } \\
\text { Intensity }\end{array}$ \\
\hline $4640.64 \ldots$ & 0.360 & 2715.19 . & 0.023 \\
\hline $4641.96 \ldots$ & 0.060 & 2714.88 & 0.117 \\
\hline $4634.17 \ldots$ & 0.300 & 4097.32. & 0.117 \\
\hline $2714.75 \ldots \ldots$ & 0.140 & $4103.38 \ldots$ & 0.082 \\
\hline
\end{tabular}

\section{REFERENCES}

Adams, T. F. 1972, Ap. J., 174, 439.

Auer, L. H., and Mihalas, D. 1972, Ap. J. Suppl., 24, 193.

Baldwin, J. 1975, Ap. J., 201, 26.

Boksenberg, A., and Penston, M. V. 1976, M.N.R.A.S., 177, 127P

Bonilha, J. R. M., Ferch, R., Salpeter, E. E., Slater, B., and Noerdlingler, P. D. 1979, Ap. J, 233, 649 .

Brocklehurst, M. 1971, M.N.R.A.S., 153, 471.

Chan, Y. W., and Burbidge, E. M. 1975, Ap.J., 198, 45.

Collin-Souffrin, S., Delache, Ph., Dumont, S., and Frisch, H. 1981, Astr. Ap., 104, 264.

Davidson, K., and Netzer, H. 1979, Rev. Mod. Phys., 51, 715.

Deguchi, S. 1985, Ap. J., 291, 492.

Eastman, R. G., and MacAlpine, G. M. 1985, Ap. J., 299, 785.

Elitzur, M. 1982, Ap. J., 262, 189.

1984, Ap. J., 280, 653

Elitzur, M., and Netzer, H. 1985, Ap. J., 291, 464.

Ferland, G. J., and Netzer, H. 1979, Ap. J., 229, 274.

Grandi, S. 1983, Ap. J., 268, 591.

Harrington, J. P. 1972, Ap. J., 176, 127.

Hummer, D. G., and Kunasz, P. B. 1980, Ap. J., 236, 609.
Kallman, T, and McCray, R. 1980, Ap. J., 242, 615.

Kallman, 1982, Ap. J.Suppl., 50, 263.

Kastner, S. O., and Bhatia, A. K. 1984, Ap. J., 287, 945.

Kwan, J., and Krolik, J. H. 1981, Ap. J., 250, 478.

MacAlpine, G. M. 1981, Ap. J., 251, 465.

Netzer, H. 1974, M.N.R.A.S., 169, 579.

. 1975, M.N.R.A.S., 171, 395.

-. 1985, Ap. J., 289, 451.

Netzer, H., and Davidson, K. 1979, M.N.R.A.S., 187, 871.

Netzer, H., and Ferland, G. J. 1984, Pub. A.S.P., 96, 593.

Nussbaumer, H. 1971, Ap. J., 170, 93.

Osterbrock, D. E. 1981, Ap. J., 246, 696.

Saraph, H., and Seaton, M. J. 1980, M.N.R.A.S., 193, 617.

Seaton, M. 1968, IAU Symposium 34, Planetary Nebulae, ed. D. E. Osterbrock and C. R. O'Dell (Dordrecht: Reidel), p. 130

- 1978, M.N.R.A.S., 185, 5P.

Shuder, J. M., and MacAlpine, G. M. 1979, Ap. J., 230, 348.

Shuder, J. M., and Osterbrock, D. E. 1981, Ap. J., 250, 55.

Weymann, R. J., and Williams, R. E. 1969, Ap. J., 157, 1201

Wills, B. J., Netzer, H., and Wills, D. 1985, Ap. J., 288, 94.

Moshe Elitzur : Department of Physics and Astronomy, University of Kentucky, Lexington, KY 40506

GARY J. Ferland: Astronomy Department, Ohio State University, Columbus, OH 43210

HaGai Netzer: Royal Greenwich Observatory, Herstmonceux Castle, Hailsham, East Sussex, BN27 1RP, UK 